\title{
POLÍTICA PÚBliCA E A NORMA POLÍtica
}

Cristiane Derani*

RESUMO: O artigo inicia com a análise da função política do Estado e suas transformações, para chegar à ação estatal fundada nas políticas públicas. Destaca na construção de tais políticas a questão da democracia e aponta a importância da Constituição para a realização de ações que possam ser adequadas à consecução dos direitos fundamentais.

\section{SURGIMENTO}

A política pública é um fenômeno oriundo de um determinado estágio de desenvolvimento da sociedade. É fruto de um Estado complexo que passa a exercer uma interferência direta na construção e reorientação dos comportamentos sociais. O Estado passa para além do seu papel de polícia e ganha uma dinâmica participativa na vida social, moldando o próprio quadro social por uma participação distinguida pelo poder de impor e pela coerção.

O Estado moderno surge para dar garantia e segurança nas relações burguesas que se desenvolviam confrontando-se com a organização feudal. Com a monopolização da força e das normas de proceder, é o Estado

* Doutora em Direito. Professora de Direito Ambiental na USP. quem finca os limites do exercício da liberdade e os faz respeitar. Com isto esperava-se a paz sociál e o bem-estar dos cidadãos, o que não se concretizou.

Atuações mais profundas foram reclamadas desta organização, que passaram a ocorrer mediante determinações legais. Afinal, a característica fundamental do Estado Moderno é o exercício do poder por previsão legal. A construção da legalidade e a centralização da força fazem parte desta entidade que busca por seus atos, constantemente, a legitimidade. A justificativa do mando estatal não se foca na força ou em algum outro tipo de discriminação natural ou social. É a sociedade, pela participação política, que define e justifica o mando do Estado. Assim, conjuntamente, legitimidade e legalidade se constroem e se estabelecem no espaço público. 
O marco do Estado Moderno é fundamental para a compreensão da política pública. A sociedade outorga um poder de mando àquela entidade e procura assegurar que essas ações de poder e de mando guardem certa previsibilidade no âmbito da representação política, pela via da legalidade. Tal pressuposto permanece na ação para a construção de políticas públicas, que serão políticas que partem da lei, desenvolvem-se pela lei e são exigidas e reguladas com base na lei.

O Estado Moderno consolida-se por uma identidade distinta à da sociedade civil com a qual ele se contrapõe. Com isto, o poder público se diferencia do poder privado. O poder público tem previsibilidade para o seu exercício. Seu poder é um dever legalmente atribuído. Já o poder privado é exercido segundo a liberdade de iniciativa do sujeito que, tão-somente, se submete à conformação legal do seu livre agir.

A política no seu sentido primordial não é ação do Estado. É uma ação da comunidade (ação da pólis). Quando a comunidade se torna Estado e sociedade civil, a política toma outros contornos, definem-se duas partes distintas que se relacionam de maneira mais ou menos recíproca, pois não há eqüidade. Em princípio, a relação se dá entre um poder pelo qual se formam leis e se organiza a força e sujeitos que se submetem à lei e à coerção. Esta política, todavia, que saiu do âmbito comunitário e ganhou o espaço estatal moderno se expande na evolução do Estado Moderno no século XX, para um compartilhar de intenções no espaço estatal e daqueles que ocupam o espaço e se chama sociedade civil.

Um novo espaço público se forma. Há, pois, um movimento histórico de centralização da força política e depois uma abertura, tanto na composição das forças políticas como no poder estatal que abre o seu processo de decisão para aqueles que não estão institucionalmente vinculados com as atividades burocráticas. Não obstante, este espaço público continua sendo organizado e delimitado pelo Estado no exercício de seu poder normativo.

O Estado é ele próprio uma formação social - disto não se pode esquecer. Se ele concede ou realiza algo em sociedade, na verdade ele concretiza em atos um poder que lhe fora antes outorgado. Quando ele faz é porque ele deve fazer, e este dever se origina de uma convenção sočial. O Estado só faz porque deve, e ele deve porque há uma norma que impõe aquilo que ele deva fazer. Esta norma existe como resultado de embates sociais que permitiram aquele resultado. Então, em última análise, o Estado faz aquilo que a sociedade quer que ele faça.

Conforme se configurarem os resultados dos embates sociais, teremos uma determinada configuração de deveres do Estado. Porque este é o Estado legal, Estado Moderno, Estado que tem uma representatividade. É um Estado que se faz como resultante de um processo de legitimação e decisão social não homogênea, mas uma resultante que é indeterminável. As decisões do Estado não são algo pré-dado, mas o resultado de uma determinada correlação de forças num determinado momento. Isto não significa que impera a lei do mais forte.

O Estado faz o que deve fazer, e aquilo que deve fazer é resultante de um processo social de decisão. Este processo de decisão, por sua vez, é resultante de um embate de forças. Não se pode afirmar com isto que, necessariamente, a classe dominante ou 
aquele grupo que detenha um determinado tipo de poder espelhara nas ações do Estado sua vontade. As estruturas democráticas do Estado evoluem, a fim de que ele não seja o reflexo das forças dominantes na sociedade. Isso ocorreu de fato até o século XIX, desencadeando um processo revolucionário em que se contestava o Estado por ser o "braço político da-burguesia".

No século XX, o Estado se torna político. Ele se abre à participação e assimila os embates, constituindo-se por uma composição de forças. Incorporam-se à sua estrutura as preocupações com os desníveis na forma de competências específicas para assistência e programas visando minimizar as diferenças sociais, assim com a sua imagem de representante da força social dominante.

Nesse cenário o Estado desenvolve atividade política como um processo social de decisão, ruindo a divisão estanque entre Estado e sociedade civil, passando a ser a arena e o partícipe da política forjada em contraposições e resistências. Esta nova figura e estes novos deveres de ação do Estado são construídos inicialmente pela norma constitucional, que, além dos textos organizacionais, traz a definição de ações efetivas e fins materiais a serem realizados. Funções e ações são definidas para este Estado que tem finalidades sociais a obter por sua prática.

O Estado se racionaliza porque passa a orientar suas ações para obtenção de finalidades sociais de reequilíbrio. Deixa de refletir para ser aquele que compensará e fornecerá meios para a obtenção de reequilíbrio social. Ação estatal direcionada à obtenção de fins sociais é ação racional voltada à melhoria do bem-estar.

\section{POLÍTICAS PÚBLICAS}

Enquanto o Estado era simplesmente a concentração da violência e do poder sobre os cidadãos, respaldado pela lei, espelhava em suas decisões os interesses daqueles que o integravam, tinha-se um Estado fruto de uma política de representação - ação social para a construção de uma representação de poder. Agora a atividade estatal estende-se para uma prática identificada com a finalidade social.

Para isto, há uma modificação da estrutura do Estado e das instituições, e a política passa a ser uma política de construção de novas práticas sociais. É a política do Estado Propulsivo ou Previdência, enfim Estado Social, porque não vai apenas adequar situações, mas buscará alcançar finalidades, com planejamento e criatividade. O planejamento parte da observação e passa pela eleição de prioridades. A sociedade participa do processo decisório, dentro do espaço público organizado pelo Estado.

A política é construída, assim, no ambiente estatal, na medida em que ele seja efetivamente o tomador de decisões. Sua criação se dá a partir do reconhecimento de uma situação concreta, visando à concreção futura de valores não existentes. A finalidade é o norte pelo qual deve se guiar a política. Ela representa um valor, que estará invariavelmente inscrito no texto constitucional, representando o fundamento último da atuação ética do Estado e da sociedade. A ação impositiva e coordenada para o alcance destes fins ocorre para preencher um ambiente em que tais valores não são buscados naturalmente. Enfim, a atividade de imposição de um conjunto de ações para o alcance de 
determinados valores só existe porque há necessidade de rejeição e afastamento de uma ética existente e a construção de outra ética pautada no valor buscado.

De fato, a construção de políticas públicas para a imposição concreta de valores últimos, instituídos constitucionalmente, vem, em última análise, afastando a ética liberal de realocação ótima da utilidade eficiente na busca da maior vantagem individual. O Estado do século XX rejeita esta ética e busca outra de valores fundantes da sociedade e justificadores da existência do mando estatal. Estes valores estarão no direito, porque é nele que se constrói o Estado e se justificam suas ações. No direito são colocados os valoresfinalidade, que justificarão o complexo de ações estatais para obtenção de finalidades transformadoras da sociedade. O direito, neste contexto, passa a ser essencialmente modificador para continuar estabilizador das relações sociais. Os fins sociais a serem alcançados estão no direito, assim como muitos dos meios para chegar até eles, todos na forma de norma-princípio.

A ação estatal parte do reconhecimento dos elementos e das relações sociais. Estas se movem em torno de valores e constroem uma ética. A definição de uma relação social implica a definição concomitante de determinados valores. Toda relação comporta um conjunto de valores.

A ação democrática pressupõe o outro, reconhecer o outro, compreender o outro e trabalhar com o outro. Ética de convivência social, reconhecimento em oposição à neutralização, implica a arte da convivência dos confrontos e contraposição. Desta relação social são colhidos valores que deverão ser publicizados, generalizados, universalizados. Eles comporão a política e se tornarão impositivos, por se evidenciarem na forma jurídica como princípios normativos. Aqui se constrói uma ética social e de ação estatal da qual emanam direitos, deveres e garantias. A ética social equipara-se a um quadro de prescrições normativas. No texto normativo do Estado social a ética explicita-se juridicamente como vetor de condutas públicas. Está no direito, não obstante seja construída a partir do reconhecimento dos elementos do concreto.

Definindo-se, política pública é um conjunto de ações coordenadas pelos entes estatais, em grande parte por eles realizadas, destinadas a alterar as relações sociais existentes. Como prática estatal, surge e se cristaliza por norma jurídica. A política pública é composta de ações estatais e decisões administrativas competentes.

Uma sociedade mais democrática, mais consciente, com instrumentos de maior participação, é uma sociedade em que a política pública conterá de maneira mais fiel a força decisória da sociedade. Uma sociedade poderá conter campo e competência para realização de políticas públicas, porém isto não significa que será uma política pública democrática.

A política pública surge a partir de uma construção normativa. Assim, estruturalmente a base da política é o direito.

A construção da política se dá no interior do Estado em três momentos:

1. Decisão estatal: feita por agentes públicos competentes no interior do Estado com maior ou menor participação social. Seu conteúdo e seus agentes estão circunscritos à atribuição constitucional e normativa de maneira geral. 
2. Alteração institucional: no interior da administração, mudança estrutural ou organizacional. Como exemplo de modificação estrutural, tem-se a criação das Agências como conseqüência da política de desestatização do Estado. Porém, a alteração pode ser menos visível e mesmo não implicar mudança da estrutura do Estado, mas traz novos atores privados pelo processo licitatório, atribui novas obrigações a servidores públicos - por exemplo, com a criação de um novo programa de assistência como o "leve leite". Instituição é compreendida aqui como um espaço de uma ação pública ou reconhecida publicamente pelo direito.

3. Ações públicas propriamente ditas: construção, realização de ações.

Os valores norteadores das políticas públicas são princípios normativos que dispõem sobre a ética do que deve ser e são colocados na Constituição de maneira heterogênea: são finalidades, parâmetros, diretrizes, instrumentos, como já afirmado.

Os princípios são indispensáveis para a construção das políticas públicas, seja pela indicação dos fins a serem alcançados, seja pela definição dos parâmetros da atividade política.

Fins a serem obtidos, parâmetros das ações, programas de ações - indicadores das políticas, instrumentos e caminhos para a realização das ações -, tudo isto é normatizado, inicialmente, pela Constituição. Normas reguladoras da construção de políticas públicas são normas políticas. A norma política é prescrição que traz os elementos para construção da política pública. Como e por que meios. Ela traz programas e também prescreve condutas.
Dentro dos princípios extraem-se mandamentos. Ao ler que a "ordem econômica [deve estar] fundada na valorização (...) da livre iniciativa", tem-se ao mesmo tempo um princípio e um comando de ação. O princípio da livre iniciativa se desdobra no preceito lógico de que aqueles que integram a ordem econômica - os agentes econômicos - devem se comportar de tal modo que respeitem a liberdade de iniciativa dos demãis.

A norma política, inicialmente, deve prever a competência, isto é, quem faz a política, quem estaria autorizado. A autorização implica um comprometimento. Ou seja, se a norma atribui a esferas políticas ou órgãos governamentais o poder para realizar atos e alcançar objetivos, sua execução pode ser cobrada por aqueles a quem os benefícios da realização da norma se destinam; aqueles que sofrem os efeitos da realização ou não da norma jurídica terão o direito subjetivo de reclamar a ação dos sujeitos autorizados, porque a ação lhes diz respeito.

Portanto, políticas públicas são concretizações específicas de normas políticas, focadas em determinados objetivos concretos. A norma política é o início de uma política porque ela já anunciará o quê, como e para quê fazer. Política pública usa de instrumentos jurídicos para finalidades políticas, isto é, toma os preceitos normativos para a realização de ações voltadas àqueles objetivos que se reconhecem como necessários para a construção do bem-estar.

A realização de políticas públicas pelo Estado, concretizando preceitos constitucionais, perfaz o cumprimento de um dever. Da mesma forma que compete ao Estado a ação normativa especificando as 
normas políticas constitucionais, a ele também se impõe a ação executiva.

Quando o Estado toma os valores e as autorizações previstas na Constituição e na lei ordinária e produz normas, ele se vale de seu dever de ação normativa. Contra a ação normativa infiel aos preceitos constitucionais e legais, há o controle formal dos atos normativos. Por sua vez, a ação prática deve ser examinada e questionada quanto à sua aceitação em termos dos valores e fins definidos pelo direito.

$\mathrm{Na}$ distribuição do poder estatal há o momento da elaboração dos mandamentos, o momento da realização dos preceitos normativos e aquele de averiguação, se as ações normativas e práticas estão conformes ao direito. O Judiciário será capaz de verificar a conformidade de uma norma quando ela for decorrência de um preceito genérico preexistente. Não há juízo de validade da 'norma perante valores universais, mas adequação da norma ao contexto do direito existente. Em outras palavras, a análise do Judiciário sobre a constitucionalidade de uma norma que especifica uma norma política deve estar fundada na aptidão desta norma em realizar os princípios constitucionais que ela invoca.

Uma norma política - que dispõe sobre objetivos, finalidades, instrumentos, valores não há como ser questionada materialmente, por causa de sua generalidade e abstração. Porém, desta lei-quadro decorrem ações positivas práticas e normativas prescritivas de condutas (imposições, permissões, proibições, autorizações). Neste momento é possível verificar materialmente a realização dó dever estatal de realizar políticas.
Juízo de legalidade ou constitucionalidade da política não recai sobre ela como um todo, mas sobre os textos normativos que dela emanam ou sobre as ações que elas inspiram. A política como um quadro de ações genéricas não consegúe ser questionada porque ela não chega a se impor sobre a realidade. Indispensável para o questionamento da constitucionalidade do conteúdo da norma política é a determinação do ambiente normativo, que é a referência fática verificável pela leitura do texto normativo.

Por exemplo, a disposição que prevê a progressividade do IPTU em função da utilização inadequada de imóvel urbano não pode ser questionada juridicamente em seu campo fático. Juízo sobre sua constitucionalidade só poderá ser feito no aspecto formal - se a norma do estatuto da cidade responde ou não ao previsto no art. $182, \S \S 4 .^{\circ}$, II da CF. Esta norma não cria um âmbito normativo. Por sua vez, a lei do município de São Paulo que define os galpões e armazéns situados no espaço urbano do município de São Paulo como imóveis sujeitos a uma alíquota mais elevada de IPTU, discriminando-os por julgar sua destinação inadequada ao município, cria um âmbito normativo. Neste caso, há um espaço geográfico definido, e um juízo de ocupação deste espaço se exprime pela norma prescrita, optando-se pela rejeição daquela ocupação.

Um dever ser traz junto consigo um poder ser, tem uma correlata pretensão de vir a ser. Norma política é um mandamento e, por isto, pode ser cobrada como prescrição de uma prestação positiva e pode ser questionada em seu conteúdo.

A norma constitucional que indica uma política estatal traz invariavelmente princípios 
que se desdobram em finalidades, diretrizes (caminhos), valores propriamente ditos. Esta norma tem aplicação imediata e se destina ao Estado assim como aos sujeitos que praticam os atos relacionados com a política que indica. Diversamente das chamadas normas programáticas, estas normas não se destinam apenas ao Estado, mas têm como destinatário os sujeitos sociais, pessoas físicas ou jurídicas que em suas ações encontram-se no quadro tratado pela norma constitucional, obrigando-se a construir igualmente os seus fins, a partir da adoção dos valores e meios ali retratados.

$\mathrm{Na}$ teoria constitucional brasileira, inúmeros constitucionalistas buscaram diferenciar as normas constitucionais criando classificações. ${ }^{1}$ Destaco a classificação do eminente professor José Affonso da Silva, que, quanto à eficácia e aplicabilidade, define três tipos de normas: normas de eficácia plena e aplicabilidade direta, imediata e integral; normas de eficácia contida e aplicabilidade direta e imediata, mas possivelmente não integral; normas de eficácia limitada:

a) declaratórias de princípios institutivos ou organizativos; b) declaratórias de princípio programático. $^{2}$

Não obstante a classificação, afirma o autor que "não é fácil determinar um critério para distinguir as normas constitucionais de eficácia plena daquelas de eficácia contida ou limitada". ${ }^{3}$ Aquilo que o eminente professor

\footnotetext{
1 Celso Antonio Bandeira de Melo, Celso Bastos, Luís Roberto Barroso, Pinto Ferreira, José Affonso da Silva, para citar alguns nomes.

2 Aplicabilidade das normas constitucionais. 4.ed. São Paulo: Malheiros, 2000. p.86.

3 Idem, p. 91 .
}

chama de eficácia contida refere-se à forma de sua aplicação, visto que ele afirma ser diretamente aplicável tal norma. A atuação do legislador teria o "escopo de lhes conferir plena eficácia e aplicabilidade concreta positiva". 4 Segundo ainda o autor, estas normas são limitadoras do poder público. A atividade do legislador ordinário seria de restrição:

Normas de eficácia contida, portanto, são aquelas em que o legislador constituinte regulou suficientemente os interesses relativos a determinada matéria, mas deixou margem à atuação restritiva por parte da competência discricionária do Poder Público, nos termos de conceitos gerais nelas enunciados. ${ }^{5}$

Além destas normas, o autor destaca as normas programáticas. Chama de normas programáticas aquelas a que o professor Eros Grau denomina normas-objetivo. ${ }^{6}$ Afirma que são programáticos os direitos sociais, culturais e econômicos, que necessitam de uma interferência do legislador. Ao contrário das normas constitucionais que enunciam os direitos individuais, que são de aplicabilidade imediata e direta.

Junta-se à Canotilho na formulação da seguinte questão: “como pode (se é que pode) uma constituição servir de fundamento normativo para o alargamento das tarefas estaduais e para a incorporação de fins econômico-sociais, positivamente vinculantes das instancias de regulação jurídica?"7

\footnotetext{
4 Idem, p. 104.

5 Idem, p.116.

${ }^{6}$ Cf. GRAU, E. R. A Ordem Econômica na Constituição de 1988.

7 SILVA, J.A. da. Opus cit. p.140-141.
} 
A exposição sucinta desse pensamento se fez necessária, porque é representativa da melhor doutrina do direito constitucional brasileiro. Contudo, sobre ela deve-se iniciar um esboço de crítica. Não se trata de opor-se à classificação estabelecida, porque a intenção não é substituir um enquadramento por outro. Trata-se de atualizar a interpretação constitucional, adequando-a a uma práxis de concretização que é operada pelo Estado, nos seus três níveis de poder, assim como pelos sujeitos sociais em sua atividade não estatal.

De fato, o temor revelado na questão acima deve ser desvelado, e a Constituição deve ser vista na sua força política. Há normas constitucionais - e não são poucas que impõem a construção de políticas. Isto não trai a força normativa e as origens da Carta Magna. Revela, outrossim, um desenvolvimento da norma estruturante do poder político que, além de definir a estrutura, organiza a própria atividade indicando objetivos, meios, instrumentos, diretrizes (policies). São as normas políticas propriamente ditas. Adotamos a crítica do professor Eros $\mathrm{Grau}^{8}$ à expressão programática, porém, remarcamos que estas normas não dispõem apenas de objetivos do Estado, mas prescrevem outros valores.

Sobretudo o que se deve acrescentar a essas reflexões diz respeito aos sujeitos destinatários do comando de ação. O comando de ação é complexo. Não há individualização de conduta, mas revela um campo, seus contornos e orientações, cabendo aos sujeitos

8 GRAU, E. R. Direito, conceitos e normas juridicas. São Paulo: Ed. Revista dos Tribunais, 1988. p.123-153. nas suas ações individuais adequarem-se aos elementos enunciados da ação.

Os sujeitos são indistintamente o Estado e as pessoas de direito privado, físicas e jurídicas, que, porventura, se encontrem concretamente no campo de ação tratado pelo 'dever ser' constitucional. Daí o sentido de 'política' - como qualificativo desta espécie de norma constitucional - referir-se à ação pública de sujeitos públicos e privados, que têm em comum o fato de construírem a coexistência na "polis".

Norma política é norma de ajustamento de condutas sociais, do ponto de vista macro. Não são normas que se preocupam com a pacificação de relações individualizadas, mas guardam o foco no desenvolvimento do todo.

Essas normas políticas trazem como característica a prescrição de princípiosfins, princípios-diretrizes (meios), princípiosvalores (modo), que se destinam imediatamente ao Estado e aos sujeitos privados. Não se trata de "simples programas a serem desenvolvidos ulteriormente pela atividade dos legisladores ordinários".9

A Constituição é um conjunto de normas que se servem dos elementos da realidade na sua prescrição e se destinam a construir, à sua imagem, esta realidade, pela sua aplicação. Na prescrição de normas políticas, é identificado um contexto social, por exemplo o conjunto das atividades econômicas (art. 170), as relações entre os seres humanos e o ambiente (art. 225), a ocupação do espaço

\footnotetext{
${ }^{9}$ Sulva, J. A. da. Curso de Direito Constitucional Positivo. 18.ed. São Paulo: Malheiros Editores, p. 765 .
} 
urbano (art.182) etc. Em seguida, são atribuídos os princípios fins, diretrizes, valores, visando conformar o referido contexto a um quadro constitucionalmente construído. O poder e o dever de agir na realização da configuração deste quadro estão nas mãos daqueles que diretamente agem no referido contexto e no Estado, que dentro de sua competência deve agir como poder normativo, executivo, fiscalizador e julgador. Assim, o destinatário da norma é identificado formalmente pela atribuição de competência, quando se trata do poder público, e materialmente, pela identificação dos sujeitos envolvidos no contexto retratado pela Constituição. A Constituição vincula solidariamente - mas por imposição e coerção - os sujeitos, que se tornam atores transformadores da sociedade na direção do ideal constitucional.

Uma norma política não é uma restrição imposta pelo Estado, mas sim um complexo conformativo do quadro social. O Estado Social fala por seus preceitos constitucionais conformadores da prática social e da ação política Estatal. Se a República Federativa é um Estado social democrático de direito, então políticas específicas devem ser adotadas. E o mesmo documento que declara o princípio do Estado social declara um conjunto de políticas. A Constituição não cala diante da idéia do Estado social. ${ }^{10}$ Ela a desenvolve e expõe seu conteúdo, impondo condutas políticas complexas ao Estado.

Configura-se infração à norma política ações que se manifestam sob qualquer forma,

${ }^{10}$ Cf. MÜLLER, F. Essais zur Theorie von Recht und Verfassung. Berlin: Dunker \& Humblot, 1990. p. 178-182. que produzam ou possam produzir efeitos distintos dos previstos pela norma política. Não há tipificação de uma determinada ação, na forma de "Tatbestand", na norma política, mas há determinação dos resultados e dos caminhos para estes resultados que devem ser respeitados e executados.

A teoria constitucional que traduz este movimento de dinâmica realizadora da Constituição pelos sujeitos públicos e privados, numa constante imposição e conformação do agir, é de Görg Haverkate. Para ele, a Constituição é uma ordem da reciprocidade, isto é, ela define os espaços e o conteúdo da ação pública coordenada com as demandas da atuação privada. Há duas partes principais na Constituição: regras de organização estatal e finalidades do Estado. ${ }^{11}$

Com base nesta teoria, é possível pensar as disposições sobre finalidades do Estado e das atividades sociais que estão na Constituição e são a base para a realização dos direitos fundamentais. Esta teoria se opõe à teoria formal unilateral, que apenas trata das disposições literais de mandamentos, direitos e deveres.

Na teoria da disposição unilateral do direito, expressa-se a consciência da positividade do direito de maneira especialmente aguda: o direito é algo fazível. Uma teoria da reciprocidade coloca a realização do direito sob suspeita, se mostra como um caminho tortuoso da positividade do direito, na medida em que busca, de fato, o conteúdo jurídico de proposições, o que independe de elas serem apresentadas diretamente na forma

11 Verfassungslehre - Verfassung als Gegenseitigkeitsordnung. München, Verlag C.H. Beck, 1992. p.23. 
de conduta ou na forma de princípios e direitos. ${ }^{12}$

A teoria da reciprocidade conduz para uma visão realista da formação e desenvolvimento da Constituição. A validade de uma Constituição não chega a ser esclarecida sem se recorrer ao modelo da reciprocidade, pois é por ela que se percorrem os caminhos da efetivação. A teoria da reciprocidade toma o conhecimento da legalidade do direito positivo existente na teoria da unilateralidade e o transforma, porque é capaz de captar a contextualização da discussão jurídico-política que envolve a formação e realização do direito.

Haverkate qualifica de maneira muito inspirada a Constituição como uma "razão provisória". ${ }^{13}$ Segundo o autor, a Constituição tem sido assinalada freqüentemente como uma base consensual. Melhor seria dizer: a Constiuição é uma base de dissenso consentido. Ela oferece uma regulação de como um com o outro podem disputar, seja pela apresentação de uma ordem de disputa como ordem processual, seja pela regulação daquilo que materialmente pode conter a disputa. A Constituição é uma ordem mínima que possibilita uma disputa civilizada das riquezas políticas. ${ }^{14}$ Haverkate é definitivo: "Numa Constituição, um povo organiza juridicamente seu tratamento com a incerteza coletiva". 15

A Constituição do Estado constitucional é uma ordem da reciprocidade produtiva dos cidadãos mediada pélo direito. Formalmente, ela se mostra como uma norma posta unilateralmente (conceito formal de Constituição). Materialmente, ela deve ser compreendida como a promessa recíproca dos cidadãos, como sujeitos de direito de se respeitarem e de se darem espaço recíproco para o desenvolvimento equânime de cada um (conceito material de Constituição). ${ }^{16}$

Em conclusão desta reflexão inicial sobre as normas políticas na Constituição, afirmo a necessidade de assumir-se a força normativa das normas políticas, essenciais para a construção dos direitos fundamentais. Em outras palavras, a efetivação das normas políticas é indispensável para a formação de sujeitos autônomos, capazes de visualizar no texto constitucional a efetiva possibilidade de seu futuro e não um conjunto afônico de palavras etéreas. A normatividade da norma política aporta segurança no que concerne às políticas públicas, assim como à ética e aos rumos das ações privadas.

\footnotetext{
12 Cf. HAVERKATE, G. Opus cit, p.113.

13 Idem, p. 142.
}

\footnotetext{
14 Idem, p. 143.

15 Idem, p. 153.

16 Ibidem.
} 